\title{
Justification of the neuro-fuzzy regulation in evaporator plant control system
}

\section{Mykhailo Hrama, Viktor Sidletskyi, Igor Elperin}

\author{
National University of Food Technologies, Kyiv, Ukraine
}

Keywords:

Sugar

Juice

Model

Evaporator

Neuro-fuzzy

Regulation

\section{Article history:}

Received 17.01.2019

Received in revised form 29.05.2019

Accepted 28.11.2019

\section{Corresponding}

author:

Viktor Sidletskyi

E-mail:

vmsidletskiy@

gmail.com

DOI: $10.24263 / 2304-$ 974X-2019-8-4-17

\section{Abstract}

Introduction. The purpose of the study is the determining the use of which type of regulation will achieve the best indicators of quality control for the regulation of the evaporator plant.

Materials and methods. The system of management of a five-body evaporator plant of a sugar refinery was researched. The method of synthesis of modal control was used for evaluating the results of the research.

Results and discussion. A comparison between FID and fuzzy regulator was made. Regulation of such responsible parameters as levels of concentrated juice in evaporator plant bodies, which directly affect the quality and value of manufactured products, was implemented. First, in the space of states in Matlab environment, a mathematical model was developed and the results obtained regarding the variation of the problem with respect to the initial conditions and perturbations were obtained. Due to them one can conclude that the time of the transition process is within the range from 0.8 to 1.2 seconds. However, the deviation levels in the evaporator plant bodies are too high. Secondly, a mathematical model with a PID-regulator was developed and transition processes for control schemes across all control channels were obtained. In this case, the time of transition processes is within the range of 60 seconds along the channel X1 to 145 seconds along the channel X2, but this led to a significant decrease in the deviation of levels in the bodies. Thirdly, a mathematical model with a fuzzy regulator is developed and transition processes for control schemes in all control channels were obtained. In this case, the time of transition processes is within the range from 50 seconds along the channel X1 to 110 seconds along the channel X2, which is the better result if compared to the PID regulator. Compared with the previous study, the levels in the bodies also significantly decreased. Therefore, the use of neurofuzzy regulation leads to an increase in qualitative parameters of the process compared with the system with PID-regulators.

Conclusions. The scientific substantiation of the feasibility of using neuro-fuzzy regulation during the implementation of optimal control systems is the novelty of the research results. 


\section{Introduction}

An automated control system for an evaporator plant can be characterized as a system, which requires the intervention of a process operator in the process of its operation [1]. Process operator shall make adjustments in the tasks for regulators in charge of temperature conditions, material flows. Such adjustments can be explained as a change in the technological and qualitative indicators for the components at the input of evaporator plant, as well as the need to change them at the output from the site. In the process of making changes in the operation of the automation system the operator shall consider how the adjacent areas affect the work of the evaporator plant, as well as the influence of the evaporator plant on the work of adjacent sites, for example: defecosaturation devices, vacuum devices, desuperheating and pressure reducing system of CHPP; secondary steam of the last case shall be used for heating of pressed pulps and feed water for extraction plant [2].

Evaporation plants for the sugar industry shall be usually equipped with evaporator plants with natural circulation [3]. In the latter, in case of non-compliance with the optimal mode in the process of evaporation, there is a decrease in alkalinity due to decomposition and caramelization of sucrose, which leads to the decomposition of amides such as asparagine [4]. Condensate juices (ammonia water) and evaporator vapors contain carbon dioxide, carbon monoxide and ammonia. Sugar juice contains glucose $\left(\mathrm{C}_{6} \mathrm{H}_{12} \mathrm{O}_{6}\right)$; the aforementioned factors cause a change in its properties. Once the glucose temperature reaches the mark of $160^{\circ} \mathrm{C}$ and it remains unchanged for a long time, there is a splitting off of one of two molecules of water, which is glucose anhydride $\left(\mathrm{C}_{6} \mathrm{H}_{10} \mathrm{O}_{5}\right)$ [5]. Creation of crystallized sugar out of it is impossible. In case of further increase of temperature up to $220^{\circ} \mathrm{C}$ boilings without flavor or bitter assamar (a substance formed when heating products of animal and vegetable origin) that are not capable of fermentation is formed out of sugar juice. Therefore, the production of sugar out of such substances is impossible. Therefore, it is necessary to provide the best quality control parameters in order to prevent overexposure and overheating of sugar juice [6].

\section{Analysis of recent studies and publications}

Improvement of the evaporation process is an important task. In the study [7] the author considers the model of the evaporation process, which takes into account the balance of mass and energy in the three components of the evaporation process. There is a unique surface of the distributor of the juice heater in case if the total surface of the heater is fixed. In the study [8] the linearization process of a nonlinear model consisting of 14 nonlinear levels of the primary order, which is a dynamic model of the evaporator plant, was researched. A function for changing the concentration of the product on the deviation of the flow rate of the liquid was found for the first time in this study. In the study [9] a fuzzy evaporator plant model, which reduces the computational time using a Rankine cycle based evaporator plant, was suggested. The results indicated that fuzzy technology can significantly reduce the time of calculation by predicting the outlet of the supercritical evaporator in the waste heat treatment system. In the study [10] the author argues that with the help of intelligent control it is possible to provide a faster decrease in the temperature of the casing and to achieve a more stable control of overheating in the first evaporator plant. In the study [11] it has been proved that control over the evaporation can be implemented by recycling the liquid in the evaporation section or by feeding only the liquid into the evaporator plant. In this study [12] the fuzzy PID regulator was investigated as a discrete version of the usual PID regulator. Thus, it retains the same structure, but has an independent adjustable control factor. It is proved that it is possible to improve the classical PID regulator with certain adaptive control 
ability. In this study [13] PID regulator of fuzzy logic is presented. This regulator is a fuzzy PID regulator with a computational efficient analytical scheme. The author proves that the regulator is stable with a restricted input / output. The need for upgrading the existing management systems is indicated in the study [14]. This study indicates some approaches that are used for a distributed level of control of technological processes. Explanation of these approaches is useful for better understanding of the processes that occur during the formation of a controlling influence, especially in cases when software programmers for industrial ACSs use a large number of settings for configuring the system. Such an approach is reasonable only for skilled professionals with significant work experience. However, knowledge of these processes by professionals can also provide more flexible work in structuring data. The study [15] indicates that one of the advanced methods of improving control systems is the addition of fuzzy and neuron-fuzzy logic. The method of dynamic regulation of power of steam boilers at the CHPP of low power according to the current needs of consumers is researched. Methods of dynamic power control of boiler systems were analyzed using fuzzy logic and adaptive neural networks. The use of fuzzy conclusions (the so-called fuzzy system) is one of the possible options for adjusting the boiler's power. The regulating action is formed by checking the coherence of the fuzzy rules on the actual parameters of the system. The rules are created according to the operator's experience, which reflects his / her actions when changing the technological parameters. In the study [16] the management of multiple evaporator plants with the full integration of fuzzy control and the use of wireless network sensors and actuators are described. The study [17] presents an overheating control of the evaporator plant using a fuzzy slider regulator. This research [18] presents a mathematical model for controlling overheating of the electronic evaporative expansion valve system with the explored management strategy. The study [19] indicates an analysis and simulation of the evaporator's electronic expansion valve with fuzzy adjustment, which was carried out. The model is identified by the least squares algorithm based on the minimized amount of square residues. The study [20] presents a fuzzy control for overheating of the evaporator plant. The research in the study [21] considers the use of a robust regulator in the process of evaporation. The author conducts a comparative analysis with the PID regulator and concludes that the suggested regulator provides better performance. In the study [22] a methodology for improving the use of steam was considered. In the study [23] the authors prove that the rate of evaporation decreases with time and performs a calculation, which indicates that liquid phase diffusion is a step that limits the speed for this system, in contrast to the evaporation of pure water. The study [24] presents a generalized stationary mathematical model for modeling a multichannel evaporator system. In the study [25] problems of troubleshooting industrial processes using dynamic neural networks by example of evaporator plant were considered. The considered neural network has a multilevel feed structure. In the study [26] the author researches the use of real-time optimization in the sugar plant evaporation section using methods that reduce the time for developing models. In the study [27] the authors consider the use of genetic algorithms in sugar production. The research [28] indicates the development of the structure of an automated control system using tensor methods in sugar production.

Aim and research objectives. The purpose of the study is to determine when the use of which type of regulation will achieve the best indicators of quality control for the regulation of the evaporator. The regulation of such responsible parameters as levels of concentrated juice in the evaporator's buildings, which directly affect the quality and cost of manufactured products, is carried out.

In this study it is suggested to research how the uses of neuro-fuzzy regulators in the evaporator plant control system that will improve the quality indicators of the regulatory 
process in order to improve the efficiency of the functioning of the automation system. For this purpose, it is necessary to develop in Matlab environment a mathematical model of the process of evaporation, translating it into the space of states. Next, it is necessary to develop mathematical regulators with PID and neuro-fuzzy regulators and compare the simulation results with each other.

\section{Materials and methods}

Description of the automation scheme. The research deals with mathematical modeling and simulation of automatic control of five-hull evaporation station of a sugar mill. The apparatus consists of 5 evaporators, with the same characteristics arranged in series [29]. The process of sugar production consists of several stages. In this sense, evaporation is the unit of mass transfer operation where the sugar syrup is concentrated to $65-70 \%$ CP (dry matter). This is done in multi-body evaporators, where the amount of steam used in the first evaporation enclosure is used in the following [30].

Figure 1 indicates automation diagrams of temperature control loops, pressure and level control. The temperature control circuits use a resistance thermometer (TE) with a built-in converter into a uniform signal (TT) that connects to the analog signal of the microprocessor controller (a point on the input line of the analog IA to the PLC). From the PLC, this information is transmitted to the automated workplace (AW) of the operator, namely to the mnemonic circuit (intersection with line I - display), is stored in memory (intersection with line $\mathrm{R}$ - registration), with the further possibility to view the trends of its change in time, as well as to the alarm subsystem (intersection with line A - alarm, to display to the AW operator an alarm if the temperature goes beyond the set limits).

In the automatic control and level control circuits in the evaporation enclosures, a level meter (LE) with a built-in converter into a uniform electrical signal (LT), which is fed to the analog inputs of the controller (IA), is used to measure the level. This information enters the controller automatic controller unit (intersection with $\mathrm{C}$ - automatic control), as well as the automated workstation (AW) of the operator, in which the values of the levels are displayed on the computer screen (intersection with I) in the form of bar charts and stored in memory ( $\mathrm{R}$ - logged with further trend viewer). In addition, an alarm (A) is generated if the value of the levels exceeds the set limits. The control signal produced by the controller is output from the corresponding analog outputs of the controller $(\mathrm{AO})$ in the form of a uniform electrical signal. It is suggested to choose pneumatic actuators. The signal from the controller is fed to an electro-pneumatic converter (eg LY 9e), which converts an analog unified electrical signal. In turn, the actuator (eg 9f) changes the position of the control valves. The operator can control the position of the regulator in remote (manual) mode (intersection with $\mathrm{C}$ remote control from the AW operator).In the control loops, resistance thermal converters TCM-1288 are used as sensors (1a). Pressure transducers PC-28 are used as sensors (6a) in the pressure control loop. Capacitance level indicators are used as sensors (10a) in the level control loop. The ITM-110 device, which is produced by "Microl" factory, was selected as secondary indicating device. Manual control units BRU-17 are used for switching the "Manual / Automatic" mode. Modicon M340 is used as a regulator. J4SPG1805 KRAFTtAIR pneumatic seat valves with built-in throttling valves are used as an actuator.

Real operation variables were used: flow rate, temperature, pressure, concentration and level. From a management standpoint, the process is multidimensional, with multiple inputs and outputs, highlighting the concentration of juice at the outlet of the last housing [31]. In addition, the process has nonlinear characteristics, with a delay and large interactions between variables [32]. 


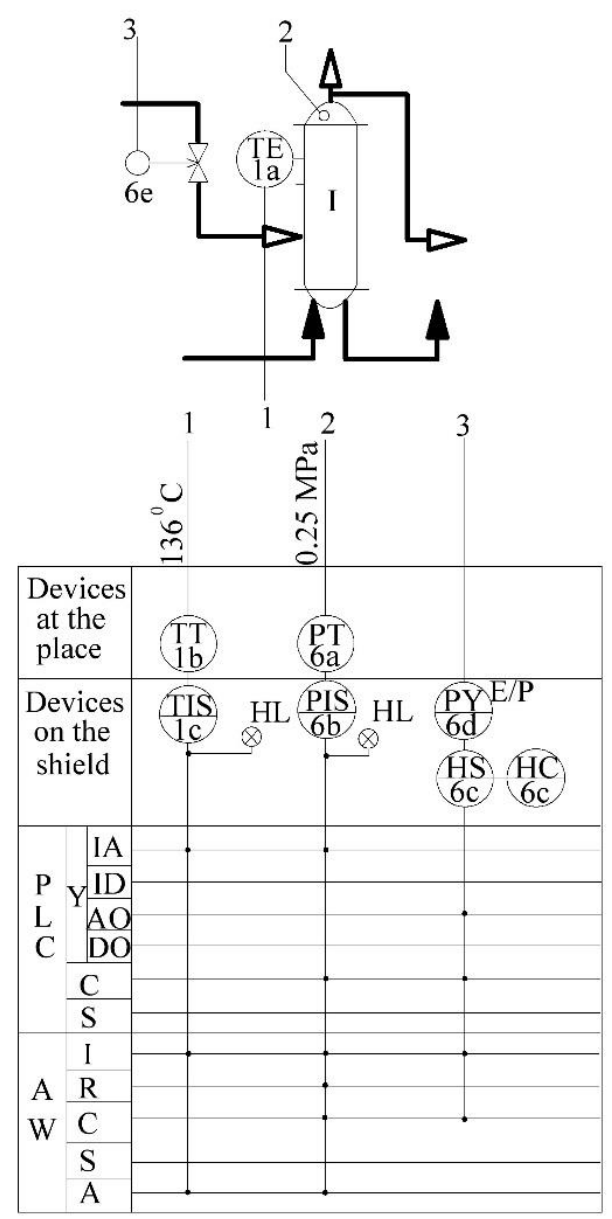

$a$
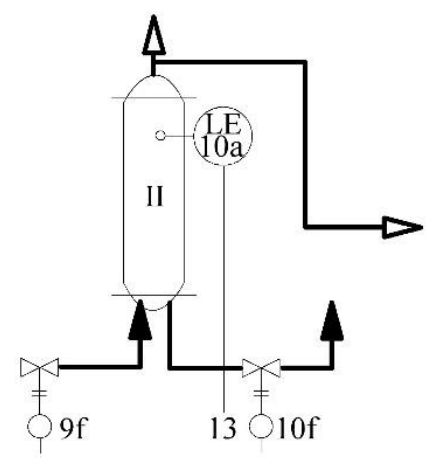

12 14

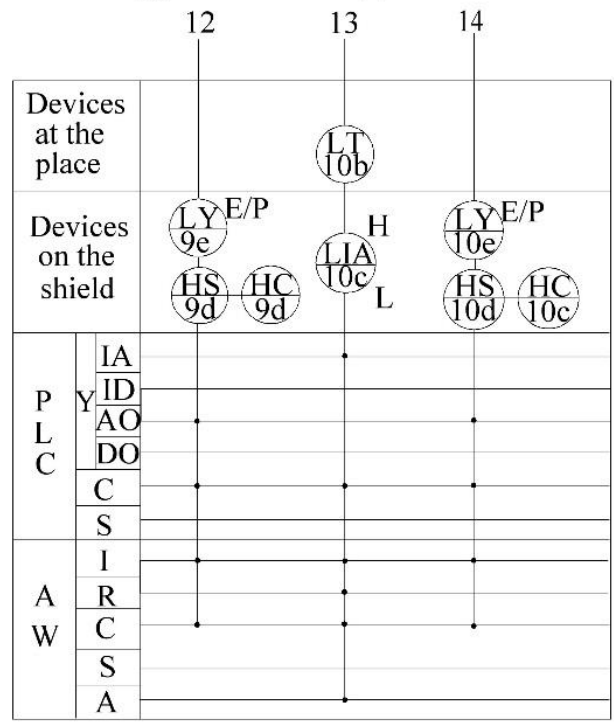

b

Figure 1. Automation of evaporator plant control loops: $a$ - temperature and pressure, $b$ - level

This research uses PIDs and neuro-fuzzy regulators. Neuro-fuzzy regulators are based on fuzzy logic. In order to develop a neuro-fuzzy regulator, it is necessary to first define the input linguistic variables [33]. The next step is to define the linguistic variable that you want to get as a result. The final step is to define the rules for converting the resulting variable from the input [34].

A modal control synthesis method will be used to evaluate the results of the work. In order to achieve the necessary transitional character, modal control changes the eigenvalue module of the object matrix. In doing so, the task itself is to select such feedback that provides the necessary distribution of the roots of the characteristic equation in a closed system [35]. Therefore, in such systems, the required number of transients is achieved not through the use of corrective links, but through the introduction of appropriate feedback on the state of the object [36]. 
Description of the method of synthesis of modal control. In order to create a mathematical model, one shall take into account the following assumptions: due to the disturbance channels and the delay control in the juice pipeline, it should not be taken into account as insignificant for the dynamics of the evaporator plant; the parameters included in the equation are taken regardless of time and is average for the bodies; the evaporator plant shall be considered as an object with concentrated parameters as a link of complete mixing [37]. One shall transfer the control object to the space of the state variables. In order to do this, one shall first write down vectors (each component of the vector), i.e. $x(t), u(t), w(t)$. Further, based on the mathematical model in the space of the state variables (1) and the system of differential equations (7)

$$
\begin{aligned}
& \dot{x}(t)=A x(t)+B u(t)+F w(t), \\
& y(t)=C x(t) .
\end{aligned}
$$

Then we receive a stationary reverse $(7)$ connection:

$$
u(t)=-K x(t)
$$

where $\mathrm{K}$ - matrix, which has an order of $\mathrm{m} \times \mathrm{n}$.

Equation of object (8) can be rewritten as follows:

$$
\dot{x}(t)=A x(t)-B K x(t)=[A-B K] x(t)
$$

Then the MATLAB environment is used [38]. Matrices are created on the basis of expressions (7-11), using the synthesis of modal control. We introduce matrices: matrices A and $\mathrm{D}$ models have components that are equal to zero.

$$
\text { Matrix } \mathrm{C}=\operatorname{diag}(1,1,1,1,1)
$$

$$
\begin{gathered}
B=\left|\begin{array}{ccccc}
-0.2277 & 0 & 0 & 0 & 0 \\
0.1466 & -0.1466 & 0 & 0 & 0 \\
0 & 0.1978 & -0.1978 & 0 & 0 \\
0 & 0 & 0.2011 & -0.2011 & 0 \\
0 & 0 & 0 & 0.2534 & -0.2534
\end{array}\right| \\
F=\left|\begin{array}{cccccc}
0.2277 & -0.2277 & 0 & 0 & 0 & 0 \\
0 & 0 & -0.1466 & 0 & 0 & 0 \\
0 & 0 & 0 & -0.1978 & 0 & 0 \\
0 & 0 & 0 & 0 & -0.2011 & 0 \\
0 & 0 & 0 & 0 & 0 & -0.2534
\end{array}\right|
\end{gathered}
$$

The square roots of the imaginary axis of this object are on the verge of stability. This conclusion is due to the fact that the real part is equal to zero [37].

In order to construct the observation matrix Nk we shall use the following method: using the ctrb function, the input parameters of which are matrices A and B. We use the built-in rank function for determining the rank of the matrix $\mathrm{Nk}$ : $\mathrm{Nk}=\operatorname{ctrb}(\mathrm{A}, \mathrm{B}), \operatorname{rank}(\mathrm{Nk})$. The rank of the matrix is equal to 5 . Since the rank of the matrix coincides with the dimensionality of the state spaces, the object is completely observable [39]. 


\section{Results and discussion}

\section{Mathematical model of five-body evaporator plant}

In the process of development of the automation system, the main inconvenience is that there are often no clear channels of control and perturbation in the mathematical models of the evaporator plant (Figure 2).

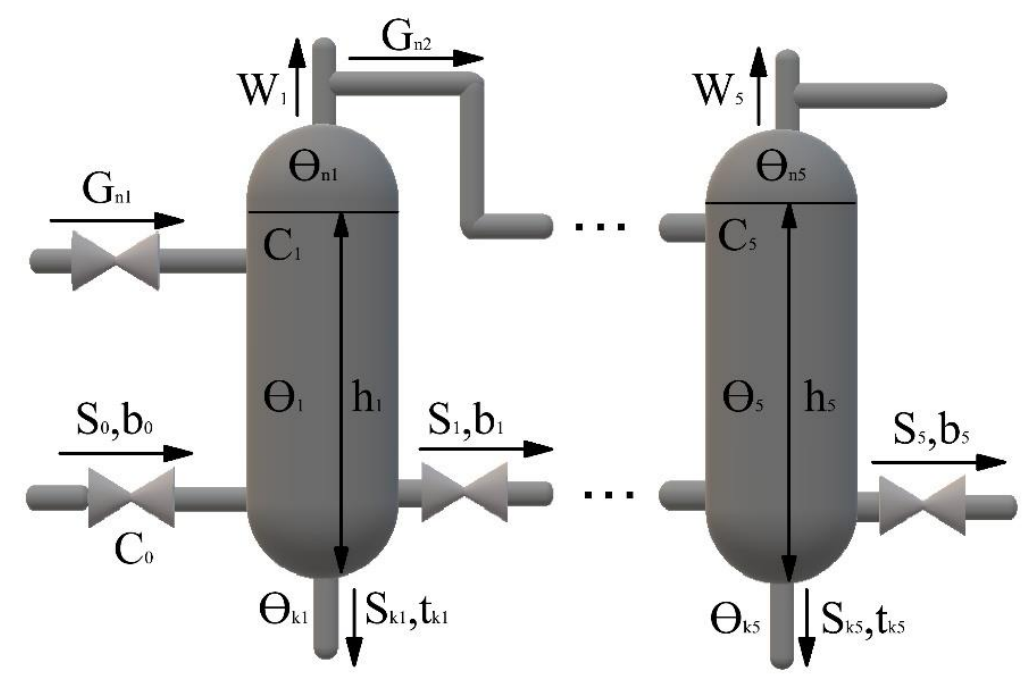

Figure 2. Mathematical model of evaporator plant:

$\Theta_{\mathrm{i}}$ - the temperature of the boiling juice in the i-th body BC $\left[{ }^{\circ} \mathrm{C}\right]$;

$\mathrm{i}=0-5-$ corresponds to the number of body $\mathrm{BC}$;

$\Theta_{\text {пi }}$ - steam temperature in the i-body of the evaporator plant $\left[{ }^{\circ} \mathrm{C}\right]$;

$\mathrm{h}_{\mathrm{i}}-$ the level of juice, respectively, in the $\mathrm{i}$-th body BC [m,\% to the length of the tubes of the surface of the heating];

$\mathrm{S}_{0}, \mathrm{~S}_{1}, \mathrm{~S}_{2}, \mathrm{~S}_{3}, \mathrm{~S}_{4}, \mathrm{~S}_{5}$ - inflow of juice into the I body, an outflow of juice from the I body and an inflow into the II body, an outflow from the II body and an inflow into the III body, an outflow from the III body and an inflow into the IV body, an outflow from the IV body and an inflow into the V body, an outflow from $\mathrm{V}$ body accordingly $[\mathrm{kg} / \mathrm{f}]$;

$\mathrm{W}_{\mathrm{i}}$ - the flow of steam generated in the $\mathrm{i}$-th body of the evaporator plant $[\mathrm{kg} / \mathrm{f}]$;

$\mathrm{G}_{\mathrm{ni}}$ - consumption of heating steam in the $\mathrm{i}$-th case $\mathrm{BC}[\mathrm{kg} / \mathrm{f}]$;

$b_{i}-$ concentration of dry matter in the i-body of the evaporator plant $[\%]$;

$\mathrm{S}_{\mathrm{ki}^{-}}-$the flow of condensate in the $\mathrm{i}$-th body of the evaporator plant $[\mathrm{kg} / \mathrm{f}]$;

$\Theta_{\mathrm{ki}}-$ condensate temperature in the i-th body $\mathrm{BC}\left[{ }^{\circ} \mathrm{C}\right]$;

$\mathrm{C}_{\mathrm{i}}-$ the content of sucrose in juice in the $\mathrm{i}$-th body $\mathrm{BC}[\%]$.

The indicated system was divided into subsystems. They are connected by essential links between variables, regulated by a similar scheme and described by mathematical models that are similar in structure.

Figure 3 shows a simplified parametric scheme for installing an evaporator plant with assigned subsystems [37]. 


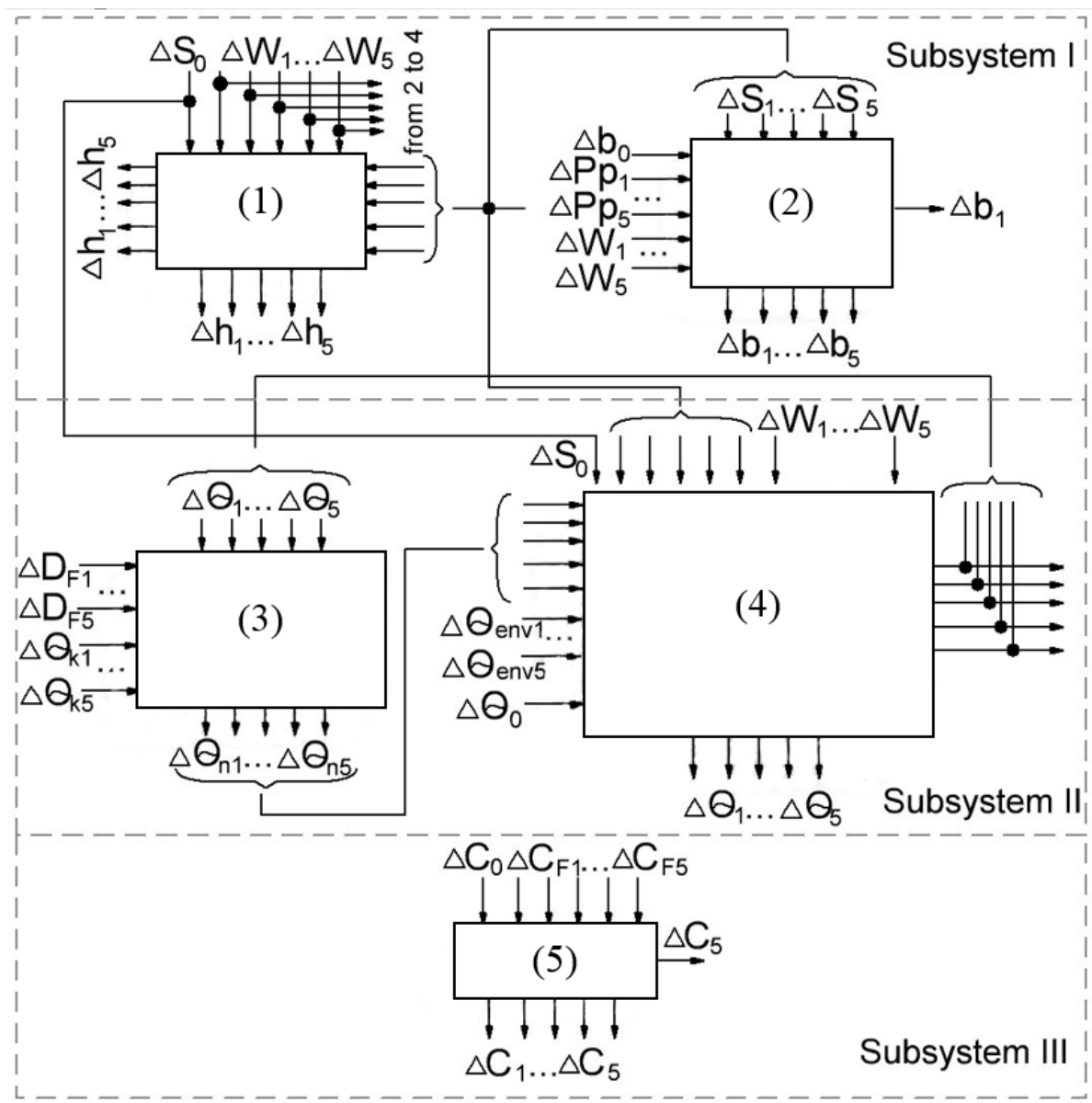

Figure 3. Parametric scheme of evaporator plant

equations describing the levels according to the bodies of the evaporator plant (7)

Below are indicated the differential equations for each of the subsystems of the nominal mode: subsystem I:

$$
\left\{\begin{array}{l}
4,391 \frac{\partial\left(\Delta h_{1}\right)}{\partial t}=\Delta S_{0}-\Delta S_{1}-\Delta W_{1}, \\
6,820 \frac{\partial\left(\Delta h_{2}\right)}{\partial t}=\Delta S_{1}-\Delta S_{2}-\Delta W_{2}, \\
5,056 \frac{\partial\left(\Delta h_{3}\right)}{\partial t}=\Delta S_{2}-\Delta S_{3}-\Delta W_{3}, \\
4,973 \frac{\partial\left(\Delta h_{4}\right)}{\partial t}=\Delta S_{3}-\Delta S_{4}-\Delta W_{4}, \\
3,974 \frac{\partial\left(\Delta h_{4}\right)}{\partial t}=\Delta S_{4}-\Delta S_{5}-\Delta W_{5} .
\end{array}\right.
$$




$$
\left\{\begin{array}{c}
187,34 \frac{\partial\left(\Delta b_{1}\right)}{\partial t}+\Delta b_{1}=-0,2 \Delta S_{0}+1,38 \Delta b_{0}+0,72 \Delta W_{1}-0,04 \Delta P p_{1}, \\
589,17 \frac{\partial\left(\Delta b_{2}\right)}{\partial t}+\Delta b_{2}=0,8 \Delta S_{1}+1,67 \Delta b_{1}+2 \Delta W_{2}-0,066 \Delta P p_{2}, \\
655,43 \frac{\partial\left(\Delta b_{3}\right)}{\partial t}+\Delta b_{3}=-1,5 \Delta S_{2}+1,5 \Delta b_{2}+4,49 \Delta W_{3}-0,1 \Delta P p_{3}, \\
1131,42 \frac{\partial\left(\Delta b_{4}\right)}{\partial t}+\Delta b_{4}=-1,67 \Delta S_{3}+1,29 \Delta b_{3}+7,46 \Delta W_{4}-0,13 \Delta P p_{4} \\
853,1 \frac{\partial\left(\Delta b_{5}\right)}{\partial t}+\Delta b_{5}=-1,01 \Delta S_{4}+1,12 \Delta b_{4}+9,37 \Delta W_{5}-0,14 \Delta P p_{5} .
\end{array}\right.
$$

equations describing concentrations according to bodies of evaporator plants, where Ppi loss of sugar during thermal decomposition in the i-th plant (8);

subsystem II:

$$
\left\{\begin{aligned}
13,89 \frac{\partial\left(\Delta \Theta_{1}\right)}{\partial t}+\Delta \Theta_{1}= & 0,1868 \Delta S_{0}+0,0482 \Delta \Theta_{0}+0,9999 \Delta \Theta_{n 1}+ \\
& +6,50 \cdot 10^{-6} \Delta \Theta_{e n v 1}-0,1792 \Delta S_{1}-0,9251 \Delta W_{1}, \\
21,78 \frac{\partial\left(\Delta \Theta_{2}\right)}{\partial t}+\Delta \Theta_{2}= & 0,1620 \Delta S_{1}+0,0315 \Delta \Theta_{1}+0,9826 \Delta \Theta_{n 2}+ \\
& +8,42 \cdot 10^{-6} \Delta \Theta_{e n v 2}-0,1394 \Delta S_{2}-0,8362 \Delta W_{2}, \\
22,50 \frac{\partial\left(\Delta \Theta_{3}\right)}{\partial t}+\Delta \Theta_{3}= & 0,2136 \Delta S_{2}+0,0266 \Delta \Theta_{2}+0,9839 \Delta \Theta_{n 3}+ \\
& +8,98 \cdot 10^{-6} \Delta \Theta_{e n v 3}-0,1794 \Delta S_{3}-1,28 \Delta W_{3}, \\
35,97 \frac{\partial\left(\Delta \Theta_{4}\right)}{\partial t}+\Delta \Theta_{4}= & 0,2948 \Delta S_{3}+0,0264 \Delta \Theta_{3}+0,9815 \Delta \Theta_{n 4}+ \\
& +1,45 \cdot 10^{-6} \Delta \Theta_{e n v 4}-0,242 \Delta S_{4}-2,1 \Delta W_{4}, \\
45,10 \frac{\partial\left(\Delta \Theta_{5}\right)}{\partial t}+\Delta \Theta_{5}= & 0,4905 \Delta S_{4}+0,0374 \Delta \Theta_{4}+0,9704 \Delta \Theta_{n 5}+ \\
& +2,58 \cdot 10^{-6} \Delta \Theta_{e n v 5}-0,386 \Delta S_{5}-4,26 \Delta W_{5} .
\end{aligned}\right.
$$

equation (9) describes the temperature of the steam-juice mixture on the bodies of the evaporator plant, where $\Theta_{\text {envi }}-$ heat loss in the environment in the i-th device $\left[{ }^{\circ} \mathrm{C}\right]$.

$$
\left\{\begin{aligned}
& 7,07 \frac{\partial\left(\Delta \Theta_{n 1}\right)}{\partial t}+\Delta \Theta_{n 1}= 0,7229 \Delta G_{n 1}+\Delta \Theta_{1}-0,0146 \Delta \Theta_{k 1}- \\
&-0,9251 \Delta D_{F 1}, \\
& 9,025 \frac{\partial\left(\Delta \Theta_{n 2}\right)}{\partial t}+\Delta \Theta_{n 2}= \Delta \Theta_{2}-0,076 \Delta \Theta_{k 2}-0,851 \Delta D_{F 2}, \\
& 8,04 \frac{\partial\left(\Delta \Theta_{n 3}\right)}{\partial t}+\Delta \Theta_{n 3}=\Delta \Theta_{3}-0,0153 \Delta \Theta_{k 3}-1,3 \Delta D_{F 3}, \\
& 13,19 \frac{\partial\left(\Delta \Theta_{4}\right)}{\partial t}+\Delta \Theta_{n 4}=\Delta \Theta_{4}-0,0138 \Delta \Theta_{k 4}-2,1445 \Delta D_{F 4}, \\
& 14,28 \frac{\partial\left(\Delta \Theta_{5}\right)}{\partial t}+\Delta \Theta_{n 5}=\Delta \Theta_{5}-0,094 \Delta \Theta_{k 5}-4,4 \Delta D_{F 5} .
\end{aligned}\right.
$$


Equations (10) describe steam temperature according to bodies of evaporator plants, where $\mathrm{D}_{\mathrm{Fi}}$ - the consumption of non-condensed gases in the i-th plant, subsystem III

$$
\left\{\begin{array}{c}
398,59 \frac{\partial\left(\Delta C_{1}\right)}{\partial t}+\Delta C_{1}=1,38 \Delta C_{0}-0,04 \Delta C_{F 1}, \\
753,49 \frac{\partial\left(\Delta C_{2}\right)}{\partial t}+\Delta C_{2}=1,67 \Delta C_{1}-0,04 \Delta C_{F 2}, \\
1399,89 \frac{\partial\left(\Delta C_{3}\right)}{\partial t}+\Delta C_{3}=1,5 \Delta C_{2}-0,1 \Delta C_{F 3}, \\
1948,73 \frac{\partial\left(\Delta C_{4}\right)}{\partial t}+\Delta C_{4}=1,29 \Delta C_{3}-0,13 \Delta C_{F 4}, \\
1523,92 \frac{\partial\left(\Delta C_{5}\right)}{\partial t}+\Delta C_{5}=1,12 \Delta C_{4}-0,14 \Delta C_{F 5},
\end{array}\right.
$$

equations (11) describe content of sucrose according to bodies of evaporator plant, where $\mathrm{C}_{\mathrm{Fi}}$ - the amount of sucrose that decomposed in the i-th plant. For subsystem III, the creation of an optimal regulator is impossible, due to the fact that it contains only coordinates of disturbances and states. That is, the subsystem is uncontrolled. Practically, only the content of sucrose $C_{5}$ in the fifth body of the evaporator plant is controlled [37].

In order to calculate the amplification matrix of the regulator $\mathrm{K}$ using the algorithm of the modulator, one shall use the built-in library function place $(\mathrm{p} 1=0,0003)$, the input parameters for which are the matrices $\mathrm{A}$ and $\mathrm{B}$, and the result is the synthesized matrix $\mathrm{K}$. The pzmap function shall be used for constructing the roots of a closed system, the input parameter for which is an object in the space of the variables of the state of ss-type, which is given using the ss format function: sys=ss(A_sys,F,C,D) (Figure 4.).

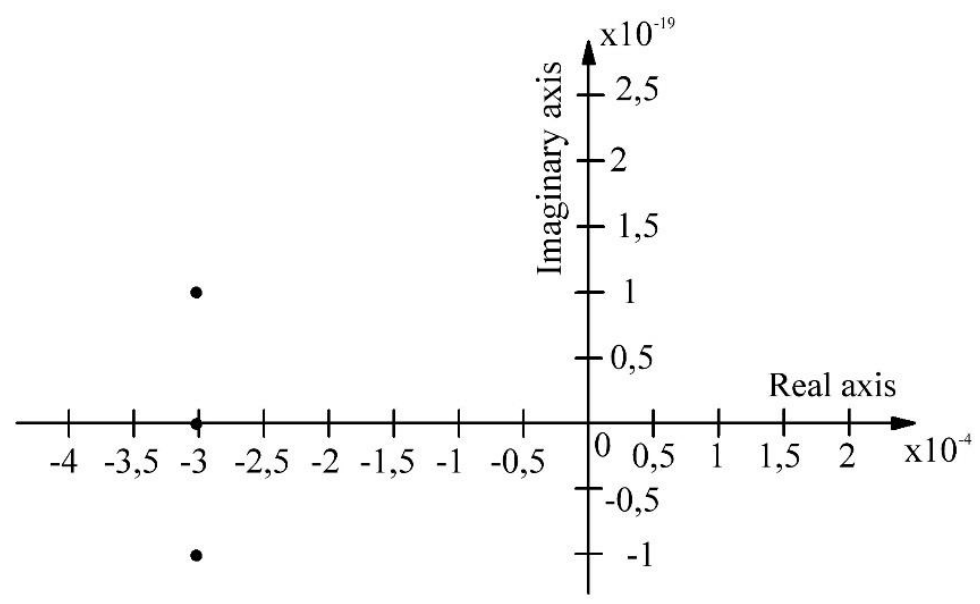

Figure 4. Pole-zero map for $\mathrm{T}=10000$ 
Consequently, the closed system is stable, since the poles are located in the left halfplane of the complex plane.

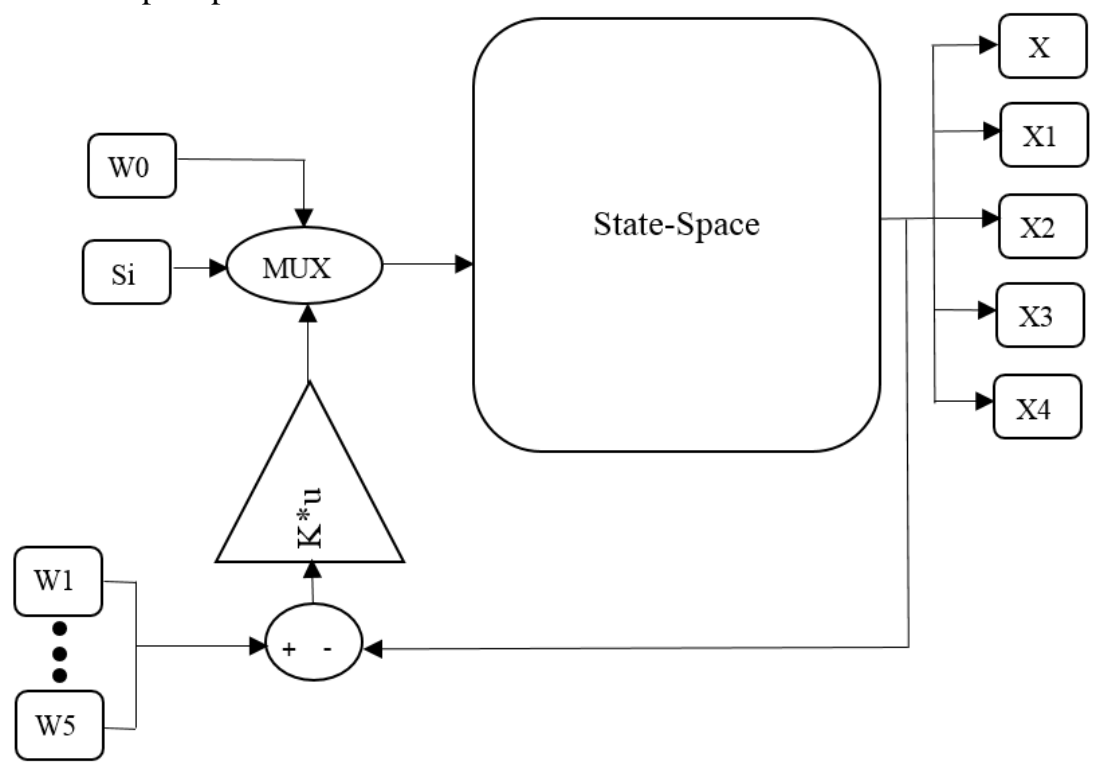

Figure 5. The schematic scheme of an object in the Simulink environment

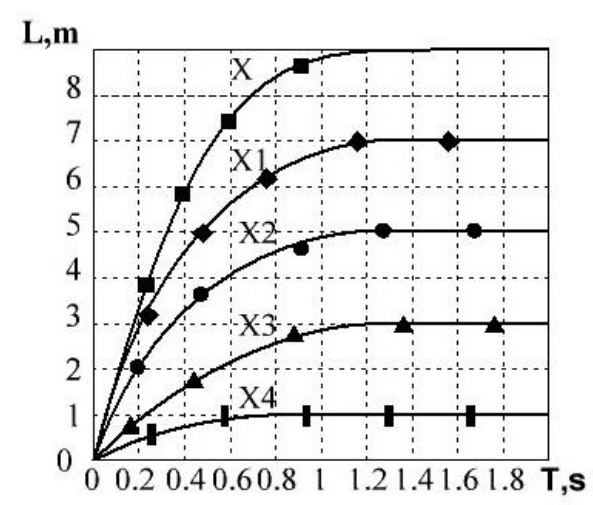

$$
\begin{gathered}
\mathrm{X} \text { - level tank I, } \\
\mathrm{X} 1 \text { - level tank II, } \\
\mathrm{X} 2 \text { - level tank III, } \\
\mathrm{X} 3 \text { - level tank IV, } \\
\mathrm{X} 4 \text { - level tank V. }
\end{gathered}
$$

Figure 6. Transition process via channels

\section{Mathematic model with PID-regulator}

Further on, in the Simulink environment, one shall use the State-Space block to enter an object in the space of the state variables in order to construct a schematic diagram of an object with a matrix regulator (Figure 5.). Due to the fact that the inputs and outputs of the State-Space block are vectors; it is additionally necessary to use the Mux and Demux blocks. The Step blocks are used for the task signals. The Initial conditions option in the State-Space object block is used for constructing the transient processes relative to initial deviations. The results for the task change are shown in Figure 6 [40].

The mathematical model with the PID regulator is shown in Figure 7. 


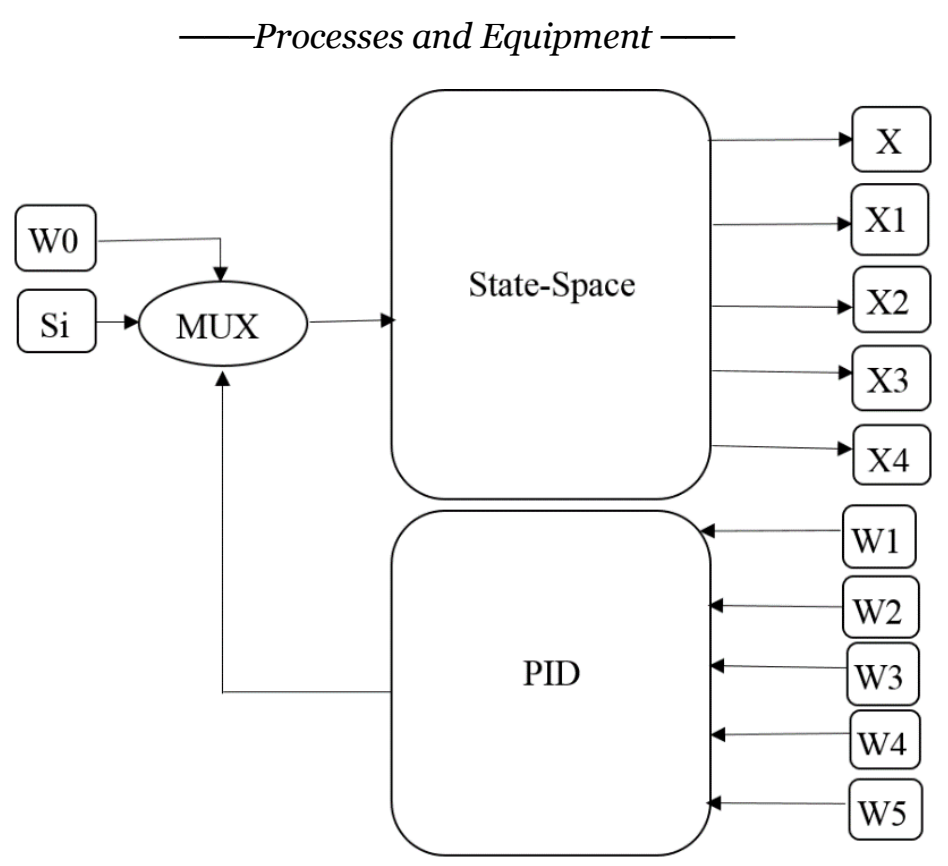

Figure 7. Mathematic model with PID-regulator

The settings for the regulator shall be calculated in the Matlab system:

By the channel X: proportional link: 1.36; integral: 0.08; differential: 0.95 ; by the channel X1: proportional: 4.85 ; integral: 0.64 ; differential: 1.47 ; by the channel X2: proportional: 0.65 ; integral: 0.02 ; differential: 0.12 ; by the channel X3: proportional: 2.38 ; integral: 0.21 ; differential: 0.9 ; by the channel $\mathrm{X} 4$ : proportional: 2.99 ; integral: 0.42 ; differential: 0.7 ;

The transition process for each adjustment channel is shown in Figure 8.

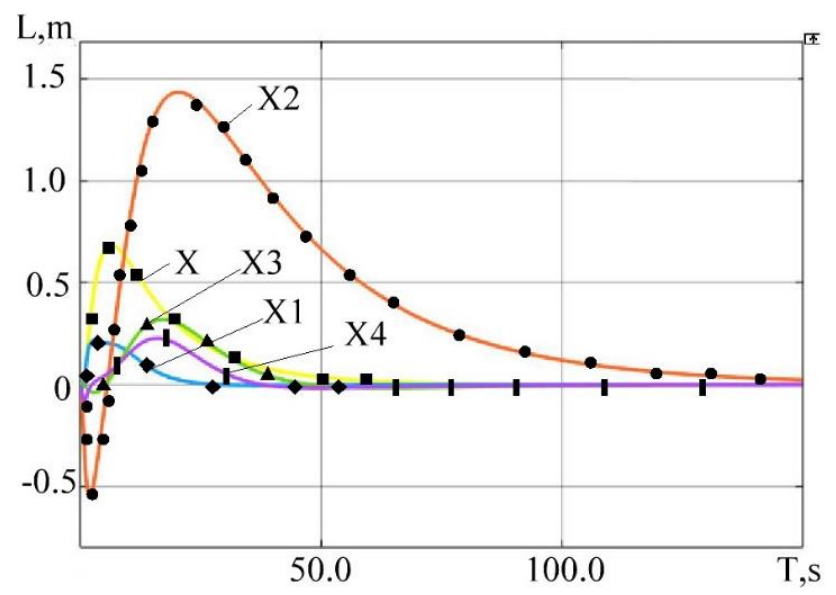

$\mathrm{X}-$ level tank I,

$\mathrm{X} 1$ - level tank II, $\mathrm{X} 2$ - level tank III, $\mathrm{X} 3$ - level tank IV, $\mathrm{X} 4$ - level tank V

Figure 8. Transition process via channels 


\section{Mathematic model with fuzzy regulator}

A mathematical model with a fuzzy regulator is shown in Figure 9.

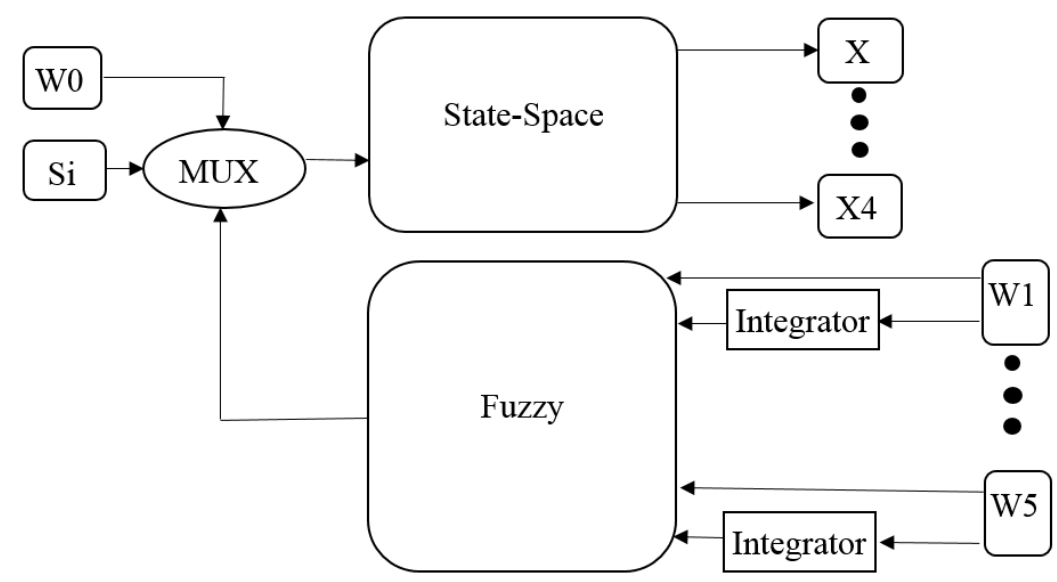

Figure 9. Mathematic model with fuzzy regulator

Setting of the fuzzy level regulator in body II is shown in Figures 10-11.
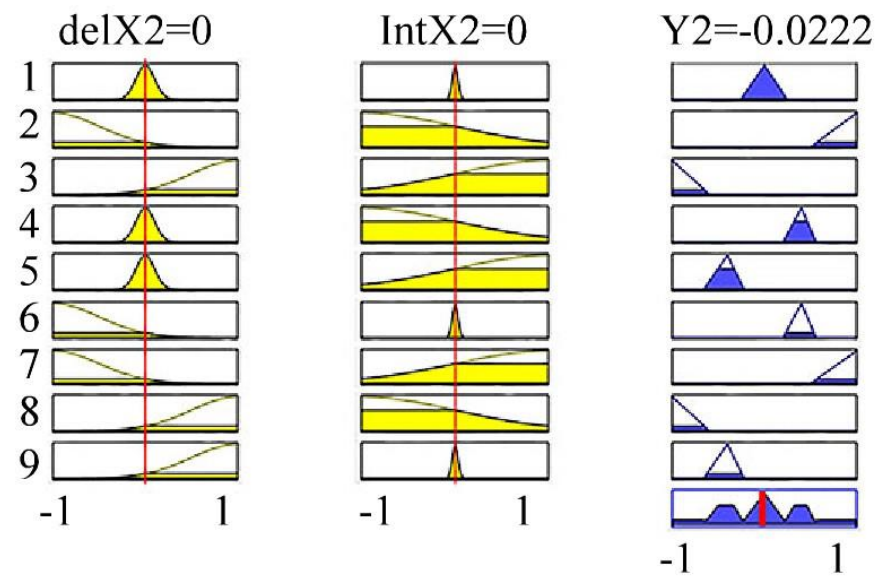

Figure 10. Graphical representation of the operation of the fuzzy conclusion algorithm: delX2 proportional term; IntX2 - integral term; Y2 - result.

Similar settings are for other fuzzy regulators. Transition processes for each adjustment channel are shown in Figure 12. 


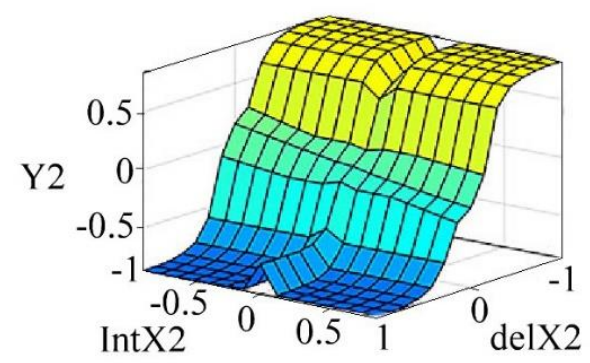

Figure 11. Reflecting surface of the response of the fuzzy algorithm: delX2 - proportional term; IntX2 - integral term; Y2 - result.

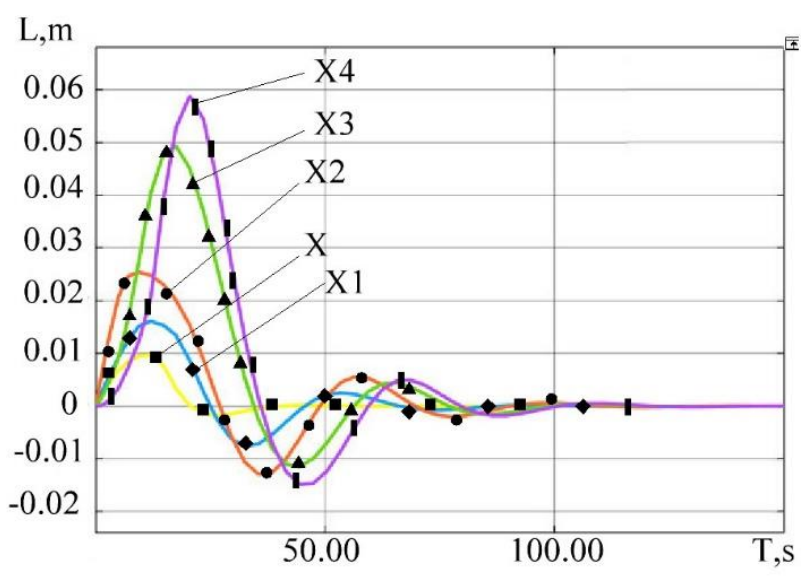

$\mathrm{X}-$ level tank I,

$\mathrm{X} 1$ - level tank II,

$\mathrm{X} 2$ - level tank III,

$\mathrm{X} 3$ - level tank IV,

$\mathrm{X} 4$ - level tank V.

Figure 12. Transition process via channels

Due to the aforementioned facts, it can be concluded that the use of a fuzzy regulator along the channel $\mathrm{X}$ gives a shorter time of the transient process (from 75 seconds with the use of the PID regulator to 55 seconds with the use of a fuzzy regulator) and a significant decrease in the amplitude of oscillations (from $0.68 \mathrm{~m}$ when using the PID regulator to 0.001 $\mathrm{m}$ using a fuzzy regulator). When comparing PID and fuzzy regulators along the $\mathrm{X} 1$ channel (Figure 13), one can see that using a fuzzy regulator one can receive a significant decrease in the amplitude of oscillations (from $0.6 \mathrm{~m}$ using the PID regulator to $0.016 \mathrm{~m}$ using a fuzzy regulator). When comparing PID and fuzzy regulators along the channel X2 it can be seen that the use of a fuzzy regulator allows for higher quality and shorter transition time (from 140 s when using the PID regulator to $110 \mathrm{~s}$ using a fuzzy regulator), a significant decrease in the oscillation amplitude (from $1.3 \mathrm{~m}$ using the PID regulator to $0.025 \mathrm{~m}$ using a fuzzy regulator). 


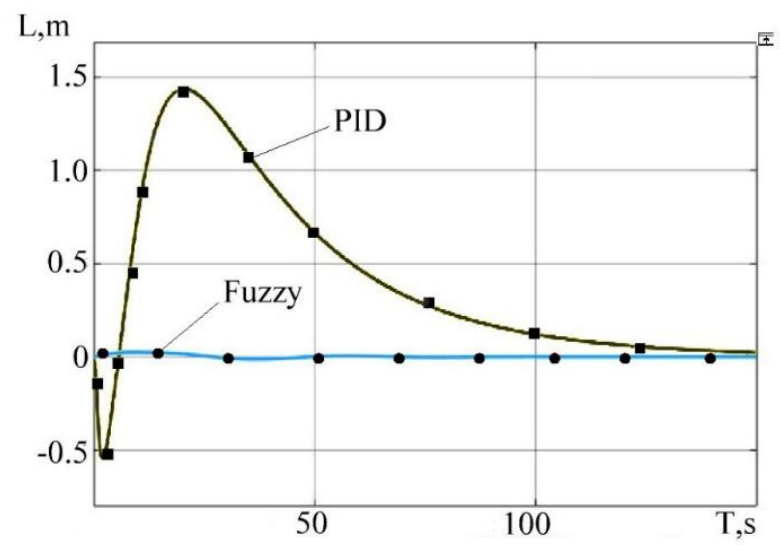

Figure 13. Transient processes of the operation of PID and fuzzy regulators (- - for PID, • - for Fuzzy)

Similarly, when comparing PID and fuzzy regulators along the X3 channel, it can be seen that the use of a fuzzy regulator allows for a shorter transition time (from $145 \mathrm{~s}$ when using the PID regulator to $110 \mathrm{~s}$ when using a fuzzy regulator) and a significant decrease in the amplitude of oscillations (from $0.25 \mathrm{~m}$ using the PID regulator to $0.05 \mathrm{~m}$ using a fuzzy regulator). When comparing PID and fuzzy regulators along the channel $\mathrm{X} 4$, it can be seen that when using a fuzzy regulator, one receives a significant decrease in the amplitude of oscillations (from $0.2 \mathrm{~m}$ when using the PID regulator to $0.06 \mathrm{~m}$ using a fuzzy regulator).

\section{Conclusion}

In order to increase the efficiency of the functioning of the automation system in this study, it was suggested to research how the use of neuro-fuzzy regulators in the control system of the evaporator plant will improve the quality parameters of the regulation process; since a number of problems will arise in case of failure to comply with the optimal mode during the process of evaporation. In this study, a comparison between PID and fuzzy regulator was made. The research was conducted in order to determine if a regulator type is used for achieving higher levels of quality of control of evaporator plant. The first step was the development of a mathematical model in the state space in Matlab environment (Figure 5). Figure 6 indicates transition processes when changing the task, it can be said that the transition time in the range from 0.8 to 1.2 seconds, which is a good result, but the values of the deviation of the levels in the cases for the evaporation process are too high $(9 \mathrm{~m}$ according to channel $\mathrm{X}, 7 \mathrm{~m}$ according to channel $\mathrm{X} 1,5 \mathrm{~m}$ according to channel $\mathrm{X} 2,3 \mathrm{~m}$ according to channel X3 and $1 \mathrm{~m}$ according to channel X4). The next step was the development of a mathematical model with the PID regulator (Figure 7). Transition processes for control loops in all five control channels were obtained as a result of the simulation (Figure 8). In this case, the time of transitions is in the range of 60 seconds according to channel X1 to 145 seconds according to channel X2. Consequently, the time of regulation has increased in relation to the previous experiment, but this led to a significant decrease in the deviations of levels in the cases $(0.68 \mathrm{~m}$ according to channel $\mathrm{X}, 0.6 \mathrm{~m}$ according to channel $\mathrm{X} 1,1.3 \mathrm{~m}$ according to channel $\mathrm{X} 2,0.25 \mathrm{~m}$ according to channel $\mathrm{X} 3$ and $0.2 \mathrm{~m}$ according to channel $\mathrm{X} 4$ ). Then a 
mathematical model with a fuzzy regulator was developed (Figure 9). Transition processes for control circuits in all control channels were obtained during the simulation (Figure 12). In this case, the time of transition processes is in the range from 50 seconds along the channel $\mathrm{X} 1$ to 110 seconds along the channel X2, which is the best result compared to the PID regulator. Compared to the previous study, the levels in the cases also decreased significantly $(0,001 \mathrm{~m}$ along the channel $\mathrm{X}, 0,016 \mathrm{~m}$ along the channel $\mathrm{X} 1,0,025 \mathrm{~m}$ along the channel $\mathrm{X} 2$, $0,05 \mathrm{~m}$ along the channel X3 and 0,06 $\mathrm{m}$ along the channel $\mathrm{X} 4)$. Thus, comparing the control channels with the PID regulator and the fuzzy regulator (for example, Figure 13), one can see that the use of fuzzy regulation significantly increases the quality of transitions, namely: in all cases, the amplitude of oscillation decreases and in almost all cases the time of the transition process decreases. Taking into account the aforementioned facts, it is obvious that the use of neuro-fuzzy regulators is more appropriate, because it results in better quality control parameters compared to the system with PID regulators.

\section{References}

1. Skakovskij Yu., Babkov. A., Mandro O. (2018), Modernizaciya strukturi sistemi keruvannya viparnoyi stancziyi buryakoczukrovogo zavodu na bazi mikroproczesornikh tekhnichnikh zasobiv i program ukrayinskogo virobnicztva, Automation of technological and business processes, 10(2), DOI: 10.15673/atbp.v10i2.972, pp. 14-15.

2. Markitan S.V. (2001), Puti povysheniya tekhniko-ekonomicheskikh pokazatelej teplovykh skhem sakharnykh zavodov, Czukor Ukrayini, 5, pp.6-7.

3. Shtanheiev K. O. (2015), Purpose installations and thermal schemes of sugar factories, UNIDO, pp. 5-6.

4. Shtangeyev K.O., Khristenko V.I. (2002), Pro raczionalne vikoristannya pari v czukrovomu virobnicztvi, Czukor Ukrayini, 2, pp. 2-3.

5. Hrama M., Sidletskyi V., Elperin I. (2019), Comparison between PID and fuzzy regulator for control evaporator plants, 2019 IEEE 39th International Conference on electronics and nanotechnology (ELNANO), Conference proceedings, pp. 54-59.

6. Leviczkij Ya.G., Dmitruk A.P., Chernyakhovskij I.B. (2001), Opyt Chortkovskogo sakharnogo zavoda po snizheniyu raskhoda topliva, Czukor Ukrayini, 5, pp.19-20.

7. Chantasiriwan S. (2017), Distribution of juice heater surface for optimum performance of evaporation process in raw sugar manufacturing, Journal of Food Engineering, 195, pp. 21-30.

8. Verma O.P., Manik G., and Jain V. K. (2018), Simulation and control of a complex nonlinear dynamic behavior of multi-stage evaporator using PID and Fuzzy-PID controllers, Journal of Computational Science, 25, pp. 238-251.

9. Chowdhury J., Nguyen B., and Thornhill D. (2015), Modelling of Evaporator in Waste Heat Recovery System using Finite Volume Method and Fuzzy Technique, Energies, 8, 12, pp. 14078-14097.

10. Jolly P.G., Tso C. P., Chia P.K., and Wong Y. W. (2000), Intelligent Control to Reduce Superheat Hunting and Optimize Evaporator Performance in Container Refrigeration, HVAC\&R Research, 6, 3, pp. 243-255.

11. Lahtinen S. (2001), Identification of fuzzy controller for use with a falling-film evaporator, Food Control, 12, 3, pp. 175-180.

12. Tang K. S., Kim Fung Man, Guanrong Chen, and Kwong S. (2001) An optimal fuzzy PID controller, IEEE Transactions on Industrial Electronics, 48, 4, pp. 757-765. 
13. Carvajal J., (2000) Fuzzy PID controller: Design, performance evaluation, and stability analysis, Information Sciences, 123, 3-4, pp. 249-270.

14. Sidletskyi V.M., Elperin I.V., Polupan V.V. (2016), Analiz ne vymiriuvalnykh parametriv na rivni rozpodilenoho keruvannia dlia avtomatyzovanoi systemy, obiektiv i kompleksiv kharchovoi promyslovosti, Naukovi pratsi Natsionalnoho universytetu kharchovykh tekhnolohii, 22(3), pp. 7-15.

15. Lapin M.V., Sidletskyi V.M. (2016), Vykorystannia system nechitkoi lohiky dlia dynamichnoho upravlinnia potuzhnistiu parovykh kotloahrehativ, Naukovi pratsi Natsionalnoho universytetu kharchovykh tekhnolohii, 22(4), pp. 24 - 31.

16. González-Potes A., Mata-López W., Ochoa-Brust A., and Escobar-del Pozo C. (2016), Smart Control of Multiple Evaporator Systems with Wireless Sensor and Actuator Networks, Energies, 9, 3, pp.142-143.

17. Zhang J., Zhang W., Hou G. (2011), Design of evaporator control system using fuzzy sliding mode controller, The 2011 Internati onal Conference on Advanced Mechatronic Systems, pp. 510-512.

18. Liu T., Wang Y., Yang X. (2013), Optimal fuzzy control of electronic expansion valveevaporator system, BioTechnology: An Indian Journal, pp. 586 - 589.

19. Bao-hua Z. (2005), Simulation and analysis of evaporator superheat electronic expansion valve fuzzy control, Energy Research and Utilization, pp. $4-5$.

20. Xiao-yang H. (2007), Fuzzy control for superheat of evaporator based on variableuniverse method, Journal of Guangxi University of Technology, pp. 7 - 9.

21. Normey-Rico J. E., Merino A., Cristea S., and de Prada C. (2005), Robust dead-time compensation of an evaporation process in sugar production, IFAC Proceedings Volumes, 38(1), pp. 460-465.

22. Lavarack B.P., Hodgson J. J., Venning J. (2004), Improving the energy efficiency of sugar factories: Case study for Pioneer Mill, International Sugar Journal, 106(1266), pp. 337-342.

23. Roger K., Sparr E., Wennerström H. (2018), Evaporation, diffusion and self-assembly at drying interfaces, Physical Chemistry Chemical Physics, 20(15), pp. 10430-10438.

24. Srivastava D., Mohanty B., Bhargava R. (2013), Modeling and simulation of mee system used in the sugar industry, Chemical Engineering Communications, 200(8), pp. 1089-1101.

25. Patan K. and Parisini T. (2005) Identification of neural dynamic models for fault detection and isolation: the case of a real sugar evaporation process, Journal of Process Control, 15(1), pp. 67-79.

26. Merino A., Acebes L. F., Alves R., and de Prada C. (2018), Real Time Optimization for steam management in an evaporation section, Control Engineering Practice, 79, pp. 91-104.

27. Polupan V., Sidletskyi V. (2018), Genetic algorithm usage for optimization of saturator operation, Ukrainian food journal, 7(4), pp. 754-762.

28. Sidletskyi V., Korobiichuk I., Ladaniuk A., Elperin I., Rzeplińska-Rykała K. (2019), Development of the Structure of an Automated Control System Using Tensor Techniques for a Diffusion Station, AUTOMATION 2019, Advances in Intelligent Systems and Computing, pp. 175-185.

29. Khomichak L. (2007), Peredovi tekhnologiyi virobnicztva czukru. Kharchova $i$ pererobna promislovist: Shhomisyachnij naukovo-virobnichij zhurnal Derzhpromu, Nacz. Universitetu kharchovikh tekhnologij ta TOV "Ukragropak", 4, pp. 20-23.

30. Borysyuk P.G. (2011), Some features of sugar market, Tsukrovi buryaky, 1, pp.4-5. 
31. Krasnyak O.P. (2012), Trends of sugar market development in Ukraine: problems and prospects, Zbirnyk naukovyh pratz Tavriyskogo derzhavnogo agrotehnologichnogo universytetu (ekonomichni nauky), 2(18), pp.261-269

32. Bondar V.S. (2010), Price trends on a world market of sugar and their influence on a domestic market of Ukraine, Tsukrovi buryaky, Available at: http://www.sugarbeet.org.ua/node/83 (Accessed 14 September 2013), pp. 9-10

33. Mudrak P.V. (2011), Price factors on a sugar market in a context of food security providing, Naukovi pratsi Poltavskoyi derzhavnoyi akademiyi, 2, pp.160-167.

34. Jantzen J. (2007), Foundations of Fuzzy Control, Wiley, pp. 152-153.

35. Besekerskij V.A., Popov E.P. (2003), Teoriya sistem avtomaticheskogo upravleniya, St. Petersburg, pp. 524-526.

36. Polupanov A.V., Romanov A.V., Frolov Yu.M. (2005), Synthesis of systems using modal control, Trudy Vserossijskoj studencheskoj nauchno-tekhnicheskoj konferenczii, Prikladnye zadachi elektromekhaniki, energetiki, elektroniki, pp. 134137.

37. Lutskaya N.M., Vlasenko L.O. (2013), Development of multidimensional optimal controllers for sugarmill evaporation plant which operates in interval indetermination conditions, Naukovi pratsi Natsionalnoho universytetu kharchovykh tekhnolohii, 52, pp. 48-61.

38. Gardner E. S. (2006), Exponential smoothing: the state of the art - part II, International Journal of Forecasting, 22 (4), pp. 637-666.

39. Hyndman Rob J., Khandakar Yeasmin (2008), Automatic Time Series Forecasting, The forecast Package for R, Journal of Statistical Software, 27(3), pp. 1-22.

40. Hyndman Rob J., Koehler Anne B., Ord J. Keith, Snyder Ralph D. (2006), Forecasting with Exponential Smoothing: the state space approach, Springer-Verlag Berlin Heidelberg, pp. 17-18. 